\title{
REBOUND ECONOMICAL AND VERTICAL STUDY FOR THE HOUSING BUILDING IN THE COASTAL ZONES
}

\section{Salem Khamis Bin Shamla}

Civil Engineering Dep. Faculty of Engineering Hadramout University

\section{Kamel Abdel Naser Ahmed.}

Arch. Dep. Faculty of Engineering Assiut University

\section{(Received January 16, 2008 Accepted February5, 2008)}

That research studied the percentage of decreasing or increasing in the cost of building by using interior height 2.70 \& 3.20 and $3.70 \mathrm{~m}$ for every floor from three Ville's (A, B and $C$ ) in the coastal zones in Hadramout Government in Yemen.

That means that the decreasing or increasing in the height of the floor is in a relationship with the cost of materials of the building, working peoples and the time of executing.

We have a result that about $12.0 \%$ to $17.0 \%$ decreasing or increasing in the total cost when we decreasing or in creasing $50 \mathrm{~cm}$ from or to the height of the floor from $3.20 \mathrm{~m}$ to $2.70 \mathrm{~m}$.

That research aims to have an economical study for the suitable height in the case of saving costs in the housing projects in urban areas in Yemen, generally for the government and specially for particular sector.

The research finished with some important results and considered that very important to put rules in the low to be legal for executing and out the suitable interior height $2.70 \mathrm{~m}$ height of the floor all for the types of buildings as (administration buildings \& Healthy B. \& Education B. \& Services B. \& Housing B. .. ect). The main aim is to realize economic in building in the urban areas in Yemen

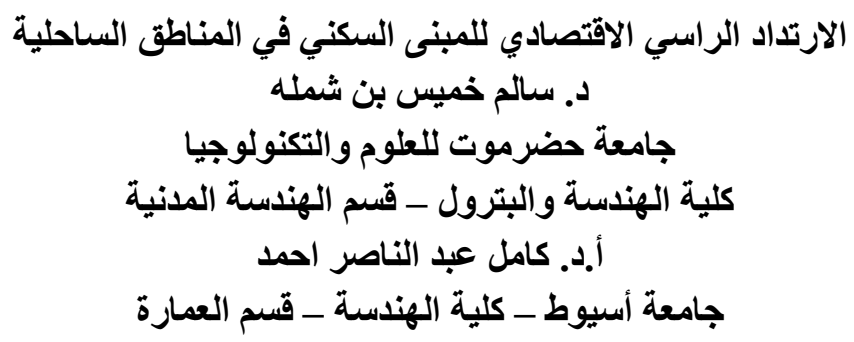




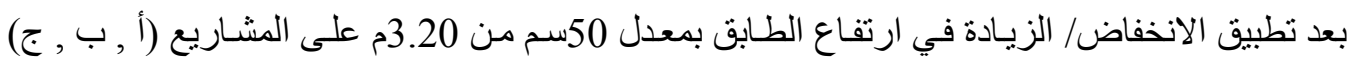

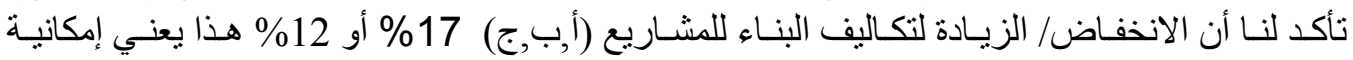

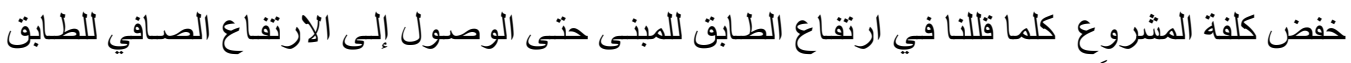

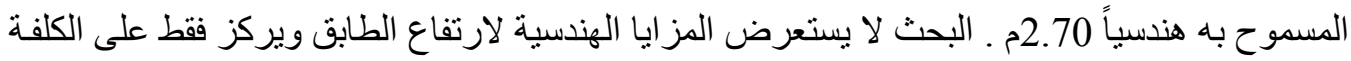

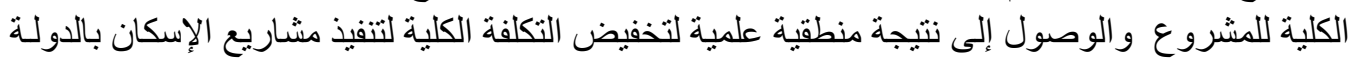

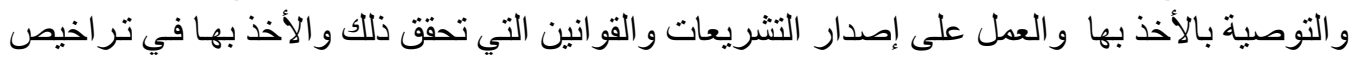

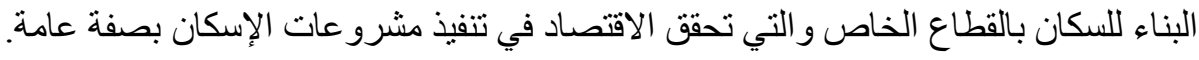

يهدف البحث :- إلى العمل على تقليل تكاليف البناء للمبنى السكني في المناطق السـاحلية واختيار الارتفاع الاقتصادي للطابق الذي يتناسب مع مساحة ووظيفة العناصر الداخلية المكونة للمشروع و الظروف البيئية

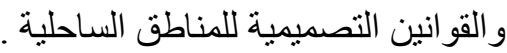
الكلمات المفتاحية : الكلفة الكلية , ارتفاع الطابق , الأعمال المحذوفة , الأعمال الإضافية .

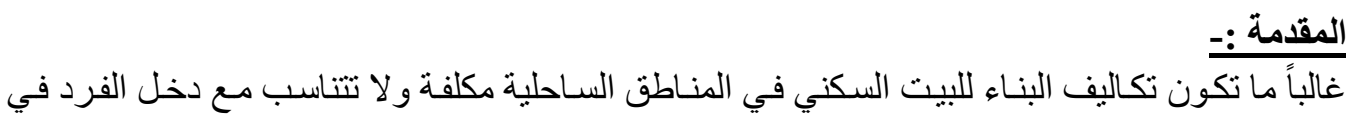

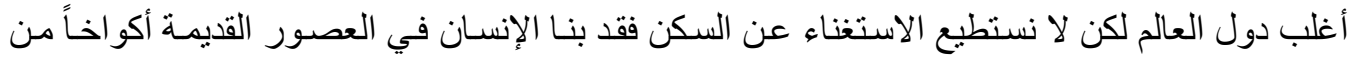

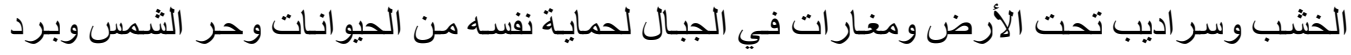

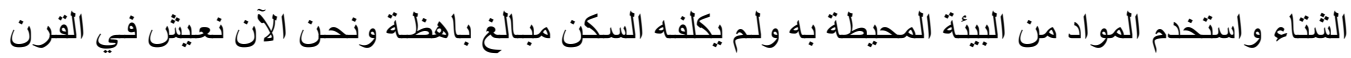

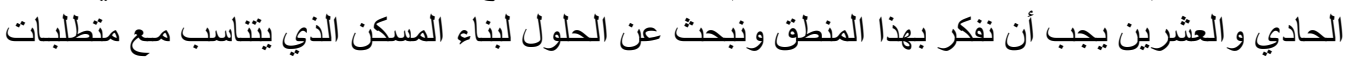

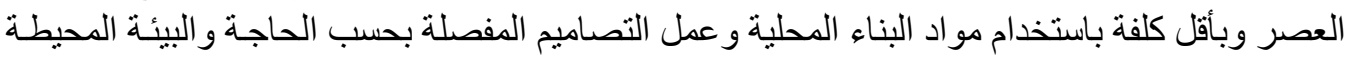

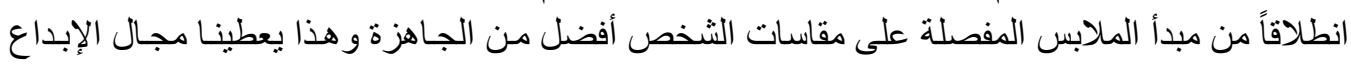

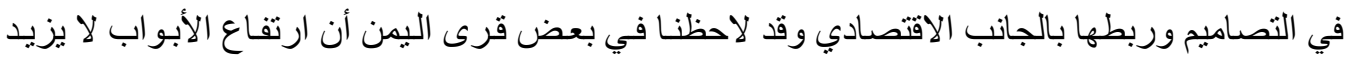

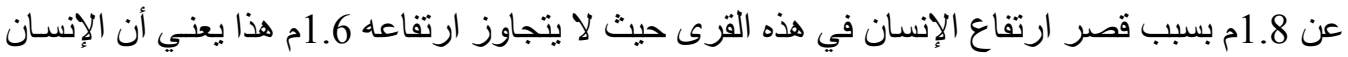

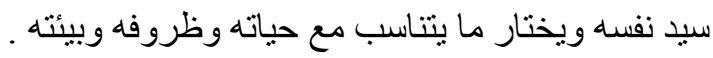

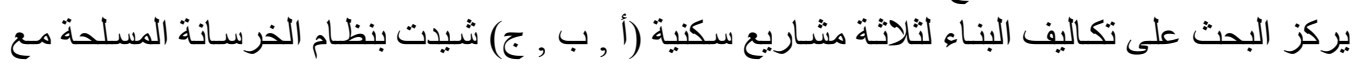

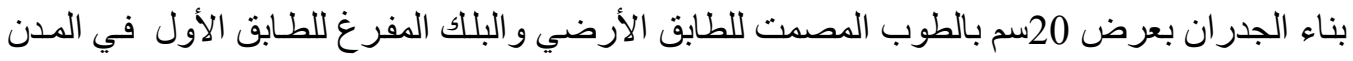

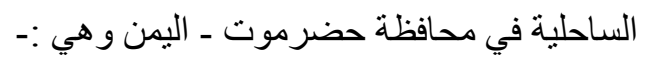

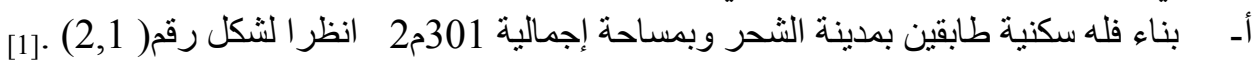

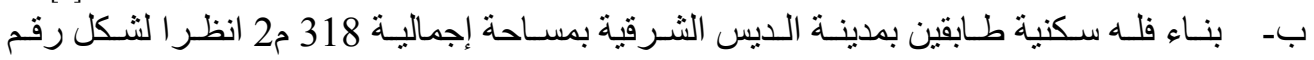

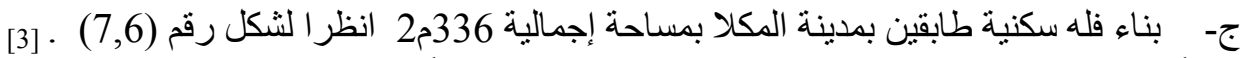

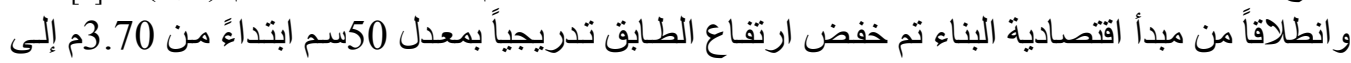

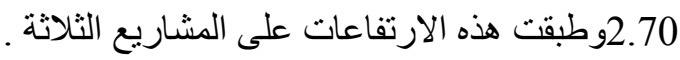

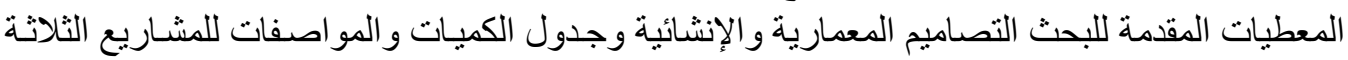

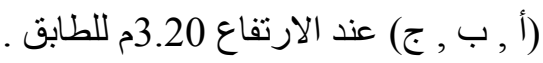


جدول رقم (1) ـ الكلفة الكلية للمشاريع (أ, ب , ج) .

\begin{tabular}{|c|c|c|c|c|}
\hline كلفة المشروع (ج) ريال & كلفة المشروع (بال ريال & كلفة المشروع & الأعمال المنفذة بالمشروع & رقم \\
\hline 344320 & 216500 & 178168 & و الرهيــز الموقــع والحفــر & 1 \\
\hline 3396578 & 3451459 & 1847675 & الأعمال الخر اسانية & 2 \\
\hline 1000537 & 2214520 & 2765240 & أعمال البناء & 3 \\
\hline 1560965 & 538704 & 626200 & أعمال التلبيس والطلاء & 4 \\
\hline 891760 & 69689 & 503172 & و أعــــــال الأرضــــــات & 5 \\
\hline 2183100 & 383500 & 645000 & الأعمال الخشبية و المعدنية & 6 \\
\hline 440000 & 332800 & 438900 & الأعمال الصحية & 7 \\
\hline 237375 & 164050 & 316850 & الأعمال الكهربائية & 8 \\
\hline 10054635 & 7998423 & 7321205 & 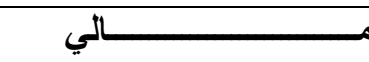 & 1 \\
\hline
\end{tabular}

منركز البحثة فيث در استه على منهجية تطبيقية لقياس وحساب التكلفة الكلية لإنثـاء وتنفيذ المباني السكنية

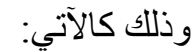

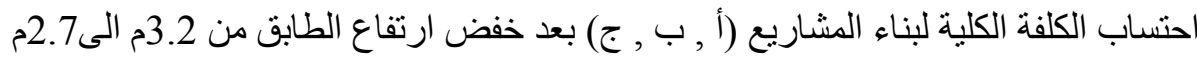

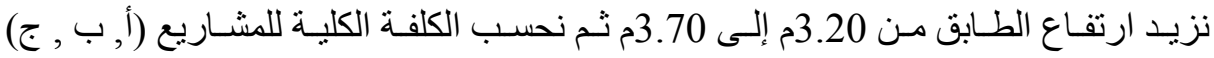

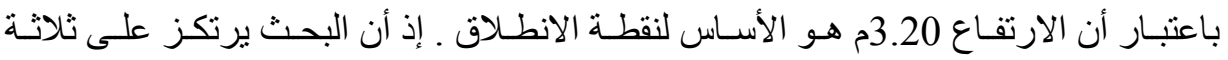

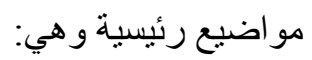

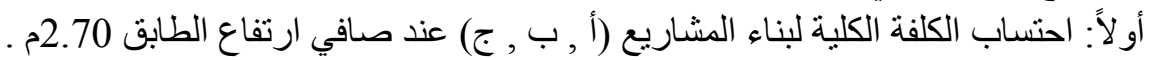

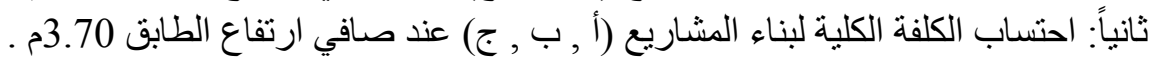

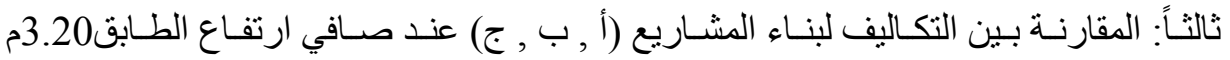
3.70, 2.70,

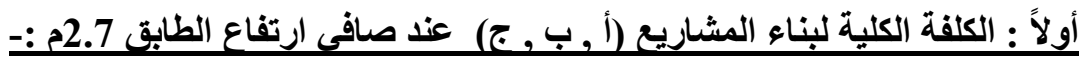

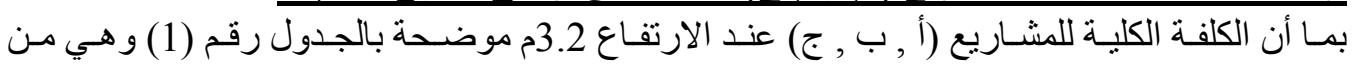

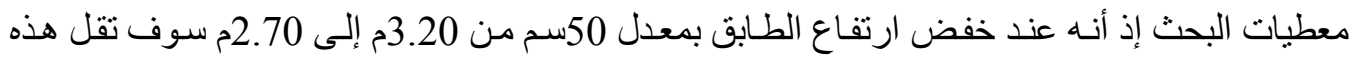
الكلفة وخصوصاً تكلفة الأعمال المرتبطة بالارتفاعات النفات وهي كالآتي :-

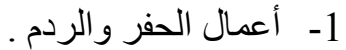

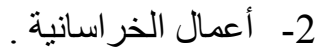

$$
\begin{aligned}
& \text { 3- أعمال البناء . العمال } \\
& \text { 4- أعمال التلبيس و الطلاء. } \\
& \text { 5- أعمال الأرضيات و السطوح (كسوة الدرج) . }
\end{aligned}
$$


و على هذا الأساس يتوجب علينا احتساب كمية الأعمال المحذوفة من البنود الخمسة السابقة للمشاريع (أ ,

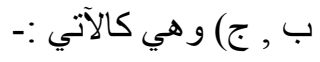

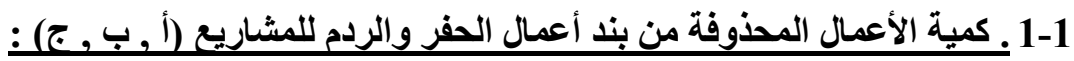

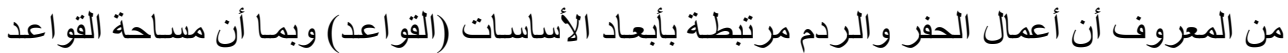

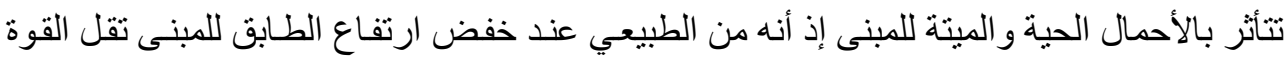

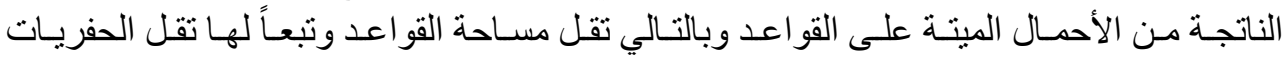

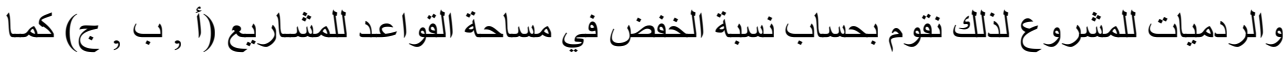

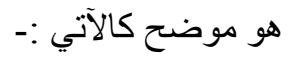

\begin{tabular}{|c|c|c|c|c|}
\hline المشرع (ج) & المشروع (ب) & المشروع (أ) & البيان & 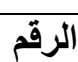 \\
\hline 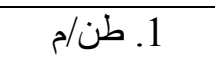 & 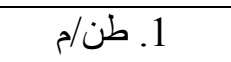 & 2.طن /م & الحمل الذاتي للأعتاب المحذوفة & 1 \\
\hline 12. طن/م & 12. طن/م & 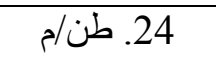 & 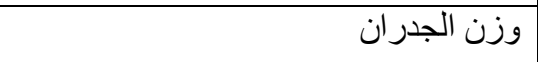 & 2 \\
\hline 22. طن/م & 22. طن/م & 44. طن/م & الوزن الكلي & 3 \\
\hline 1.76 1طن & 1.628 طن & 3.432 طن/م & رد الفعل من الأعتاب & 4 \\
\hline 12. 12 طن & 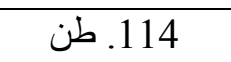 & 24. طن/م & الوزن الذاتي للعمود & 5 \\
\hline 2.162 طن & 2.038 طن & ( 4.223 طن/م & إجمالي الأحمال الميتة + 15\% & 6 \\
\hline 3.027 طن & 2.853طن & ( 5.912 طن/م & الحمل الأقصى = الأحمال الميتة × 1.4 & 7 \\
\hline 1.25 كجم/سم2 & 1.75 كجم/سم2 & 2.5 كجم/سم2 & الجهد الصافي الآمن للتأسيس & 8 \\
\hline 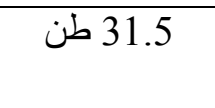 & 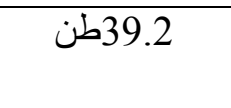 & 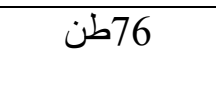 & الارتفاعل الأقصى على القو اعد قبل خفض & 9 \\
\hline ا 28.473 طن & ا & ا & الحمل الأقصى الصافي بعد خفض الارتفاع & 10 \\
\hline 22778.4 سم2 & 20770 سم2 & 28038.2 & مساحة القاعدة المسلحة بعد خفض الارتفاع & 11 \\
\hline$\% 9.6$ & $\% 7.3$ & $\% 7.8$ & نسبة الخفض في مساحة القو اعد & 12 \\
\hline $3 \curvearrowright 8.755$ & $3,3.41$ & 36.55 & كمية الأعمال المحذوفة من الحفريات & 13 \\
\hline
\end{tabular}

جدول رقم (2) ـ كمية الأعمال المحذوفة من بند الحفريات [4] (ب)

2-1 كمية الأعمال المحذوفة من بند أعمال الخرسانة المسلحة للمشاريع (أ, ب , ج) :-

\begin{tabular}{|c|c|c|c|c|}
\hline المشروع (ج) & المشروع (ب) & المشروع (أ) & الأعمال المحذوفة & 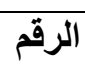 \\
\hline 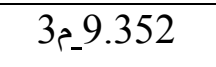 & (9.76 م3 & 11.533 & كمية الأعمال المحذوفة للأعتاب & 1 \\
\hline 912.912. & 3.024 & 32.592 & كمية الأعمال المحذوفة للأعمدة & 2 \\
\hline 2.285 & 20 2.43 & 35.616 & كمية الأعمال المحذوفة للقو اعد & 3 \\
\hline 56.56 م3 & 3.56 & 3.56 & كمية الأعمال المحذوفة للسلالم & 4 \\
\hline 13.109 & 15.774 & $3,20.301$ & ذوفة ل لخرسانة & \\
\hline
\end{tabular}
جدول رقم (3) . 


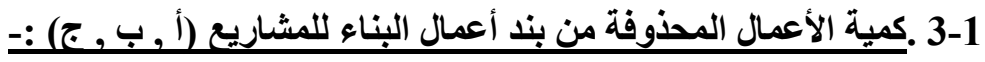

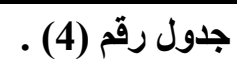

\begin{tabular}{|c|c|c|c|c|}
\hline المشروع (ج) & المشروع (ب) & المشروع (أ) & الأعمال المحذوفة & الرقم \\
\hline 93.52 & (97.6 م2 & 115.328 م2 & كمية الأعمال المحذوفة لأعمال البناء & 1 \\
\hline
\end{tabular}

4-1 كمية الأعمال المحذوفة من بند التلبيس والطلاء :-

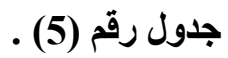

\begin{tabular}{|c|c|c|c|c|}
\hline المشروع (ج) & المشروع (ب) & المشروع (أ) & الأعمال المحذوفة & الرقم \\
\hline 187.04 م2 & 244 & 289.2 م2 & أعمال التلبيس العمال المحذوفة من بند & 1 \\
\hline 187.04 م2 & 244 & 289.2 & كمينة الأعمال المحذوفة من بند & 2 \\
\hline
\end{tabular}

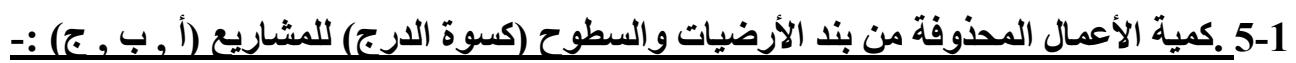

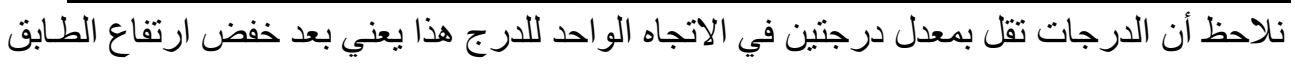

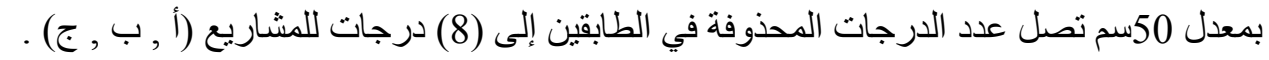

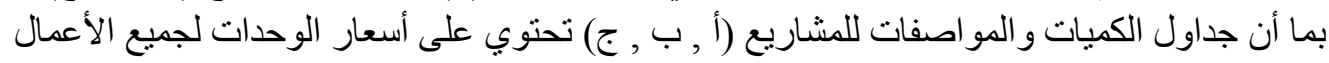

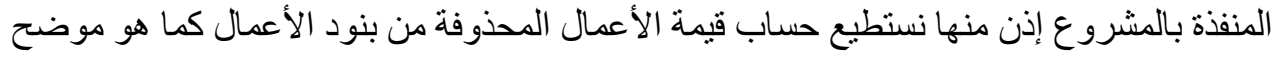

جدول رقم (6) ـ قيمة الأعمال المحذوفة / ريال يمني

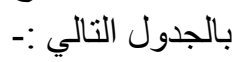

\begin{tabular}{|c|c|c|c|c|}
\hline المشروع (ج) & المشروع (ب) & المشروع (أ) & البيان & الرقم \\
\hline 8755 & 1704.6 & 16550 & أعمال الحفر و الردم & 1 \\
\hline 458815 & 552090 & 710535 & الأعمال الخر اسانية & 2 \\
\hline 180493.6 & 117120 & 155692.8 & أعمال البناء & 3 \\
\hline 258115.2 & 168360 & 318120 & أعمال التلبيس والطلاء & 4 \\
\hline 28000 & 24000 & 24000 & أعمال الأرضيات و السطوح (كسوة الدرج) & 5 \\
\hline 934178.8 & 863274.6 & 1224897.8 & إجمالي قيمة الأعمال المحذوفة & \\
\hline
\end{tabular}

بمعر فة قيمة الأعمال المحذوفة لبنود الأعمال من (1 إلى 5) للمشاريع (أ , ب , ج) ج) و الموضحة بالجدول

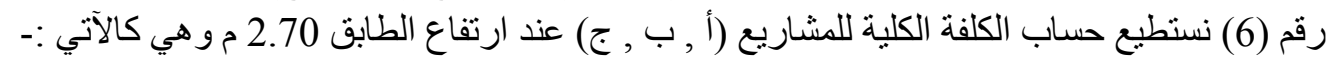

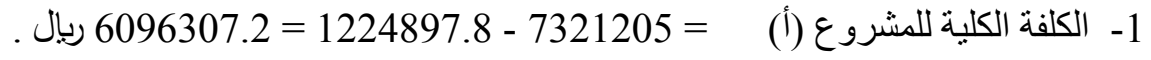

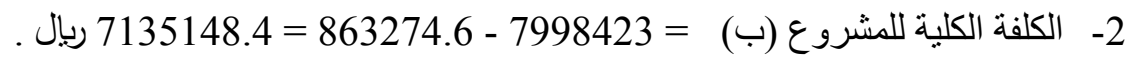
3- الكلفة الكلية للمشروع (ج) = 10054635 - 934178.8 = 9120456.2 ربال .

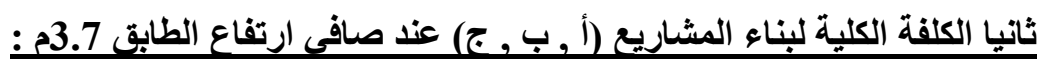

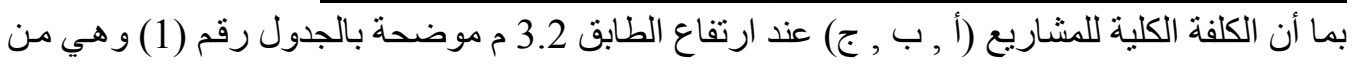

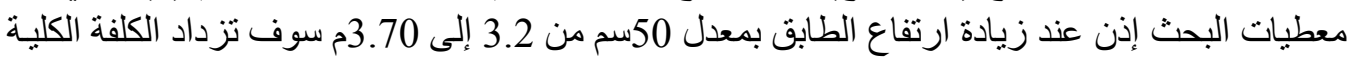


لهذه المشاريع وخصوصاً تكلفة الأعمال المرتبطة بارتفاع الطابق الدذكورة سابقا في الفقرة أو لا وبناء على ذلك يجب احتساب كميات الأعمال الإضافية لتلإلك البنود كالآتي:

\section{1-2. كمية الأعمال الإضافية لبند أعمال الحفر والردم للمشاريع (أ, ب ب. ج).}

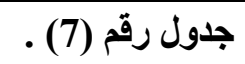

\begin{tabular}{|c|c|c|c|c|}
\hline المشروع (ج) & المشروع (ب) & المشروع (أ) & البيان & الرق \\
\hline 0.3 طن/م & 0.3 طن/م & ( ) & الوزن الذاتي للجدران & 1 \\
\hline 2.4 طن & 2.22 طن & 2.34 طن & رد الفعل & 2 \\
\hline ( ) 0.3 طن & ( ) & ( 0.3 طن & الوزن الذاتي للعمود & 3 \\
\hline 3.105 طن & 3.071 & 3.036 طن & الحمل الميت = رد الفعل + 15 & 4 \\
\hline 4.347 طن & 4.299 طن & (4.25 طن & الحمل الأقصى = الحمل الميت × 1.4 & 5 \\
\hline 31.5003ن & 39.200 طن & 76 & الارتفاع الأقصى على القاعدة قبل زيادة & 6 \\
\hline ا 35.847 طن & 43.499 طن & ن80.251 & الارتفاعل الأقصى على القاعدة بعد زيادة & 7 \\
\hline 28677.6 سم2 & 24856.6 سم & 200.4 32100س2 & مساحة القو اعد بعد الإضـافة & 8 \\
\hline$\% 13.8$ & $\% 11$ & $\% 5.6$ & نسبة الزيادة في مساحة القو اعد & 9 \\
\hline 12.586 & $3+5.137$ & 3 11.88 & كمية الأعمال الإضافية في الحفريات & 10 \\
\hline
\end{tabular}

\begin{tabular}{|c|c|c|c|c|}
\hline \multicolumn{5}{|c|}{ 2-2.كمية الأعمال الإضافية لبند أعمال الخرسانة المسلحة . } \\
\hline المشروع (ج) & (بشروع (المش) & المشروع (أ) & الأعمال الإضافية & 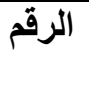 \\
\hline $3 ; 3.284$ & 3.661 & 34.032 & كمية الأعمال الإضافية للقو اعد & \\
\hline 322.28 & $3,3.78$ & 3 3.012 & كمية الأعمال الإضافية للأعمدة & \\
\hline $3 \curvearrowright 0.3$ & $3>0.3$ & $3>0.3$ & كمية الأعمال الإضافية للسلالم & \\
\hline $3,5.864$ & 3 ; 7.741 & 3.352 & إجمالي الأعمال الإضافية لبند الخرسانة المسلحة & \\
\hline
\end{tabular}

3-2. كمية الأعمال الإضافية لبند أعمال البناء للمشاريع (أ, ب ب, ج) كالآتى :

$$
\begin{aligned}
& \text { 288.32= }
\end{aligned}
$$

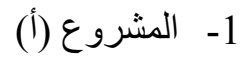

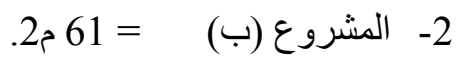

$$
\begin{aligned}
& \text { 3- المشروع (ج) }
\end{aligned}
$$

4-2.كمية الأعمال الإضافية لبند أعمال التلبيس والطلاء بالمشاريع (أ ب, ب. ج) كالتالى :

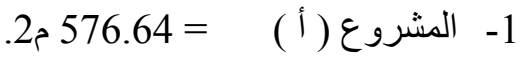

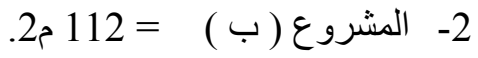

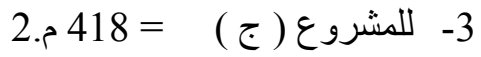


5-2.2 كمية الأعمال الإضافية لبند أعمال الأرضيات و السطوح ( كسوة الدرج ) للمثـاريع (أ ب ب . ج)

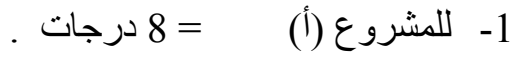

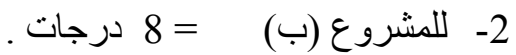

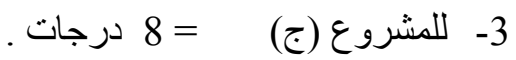

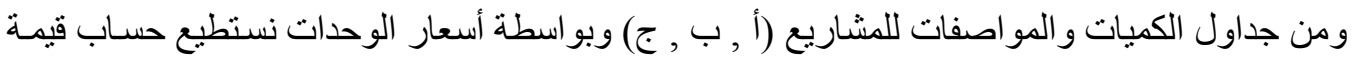
الأعمال الإضافية للبنود من (1 إلى 5) كما يلي :

جدول رقم (9) ـ قيمة الأعمال الإضافية/ربال يمني

\begin{tabular}{|c|c|c|c|c|}
\hline المشروع (ج) & المشروع (ب) & المشروع (أ) & 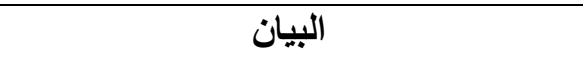 & 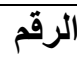 \\
\hline 12586 & 2568.5 & 11881 & أُعمال الحفر والردم & 1 \\
\hline 205240 & 270935 & 260820 & الأعمال الخر اسانية & 2 \\
\hline 403270 & 36600 & 389232 & أعمال البناء & 3 \\
\hline 576840 & 89060 & 634304 & أعمال التلبيس وطلاء & 4 \\
\hline 24000 & 24000 & 24000 & أعمال الأرضيات و السطوح ( كسوة الدرج ) & 5 \\
\hline 1.225 .936 & 423163.5 & 1.320 .237 & إجمالي قيمة الأعمال الإضـافية & 6 \\
\hline
\end{tabular}

إذن الكلفة الكلية للمشاريع (أ , ب , ج) عند ارتفاع الطابق 3.7م يمكن احتسابها بواسطة قيمة الأعمـال الإضافية الموضحة بالجدول أعلاه . الكان.

$8641442+1320237+7321205=$

. $8421586.5=423163.5+7998423=$

. $11276571=1221936+10054635=$

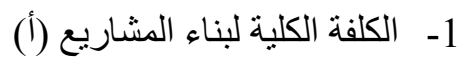

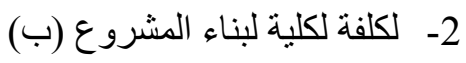

3- الكلفة الكلية لبناء المشروع ليناء الشروع) (ب)

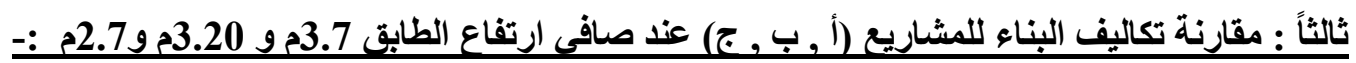



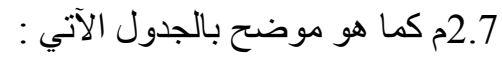

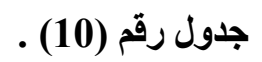

\begin{tabular}{|c|c|c|c|c|}
\hline كلفة لمشروع (ج) & كلفة لمشروع (ب) /ريال & كلقة لمشروع (أ) /ريال & الطابق & الرقم \\
\hline 912456.2 & 7135148.4 & 6096307.2 & 22,70 & 1 \\
\hline 10054635 & 7998423 & 7321205 & 3.20 & 2 \\
\hline 11276571 & 8421586.5 & 8641442 & م3.70 & 3 \\
\hline
\end{tabular}

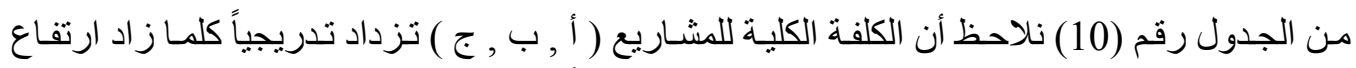

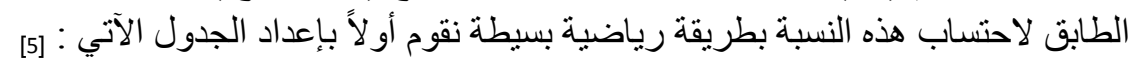




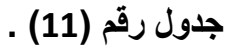

\begin{tabular}{|c|c|c|c|}
\hline ارتفاع الطابق (j) & $2.7 \mathrm{~m}$ & $3.2 \mathrm{~m}$ & $3.7 \mathrm{~m}$ \\
\hline 1 & $\begin{array}{c}\mathrm{C}_{11} \\
6096307\end{array}$ & $\begin{array}{c}\mathrm{C}_{12} \\
7321205\end{array}$ & $\begin{array}{c}\mathrm{C}_{13} \\
8641442\end{array}$ \\
\hline 2 & $\begin{array}{c}\mathrm{C}_{21} \\
7135148\end{array}$ & $\begin{array}{c}\mathrm{C}_{22} \\
7998423\end{array}$ & $\begin{array}{c}\mathrm{C}_{23} \\
8421586\end{array}$ \\
\hline 3 & $\begin{array}{c}\mathrm{C}_{31} \\
91220456\end{array}$ & $\begin{array}{c}C_{32} \\
10054635\end{array}$ & $\begin{array}{c}C_{33} \\
11276571\end{array}$ \\
\hline
\end{tabular}

لحسـاب نسبة الزيـادة في التكلفة عند زيـادة ارتفاع الطابق بمعدل 50سم نستخدم المعادلة الرياضية

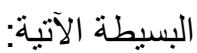

$$
\Delta \mathrm{Cij}=\mathrm{Ci} \frac{\mathrm{j}+1)-\mathrm{Cij}}{\mathrm{Cij}} \times 100
$$

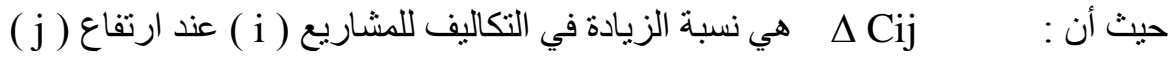

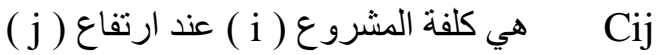

$$
\mathrm{i}=1,2,3, \ldots, \mathrm{n} \quad, \quad \mathrm{j}=1,2,3, \ldots, \mathrm{m}
$$

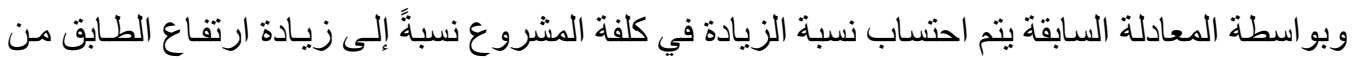

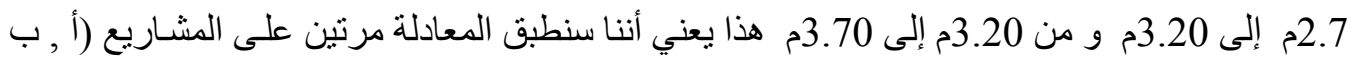
ج) فنحصل على ستة نتائج و هي كالآتي :

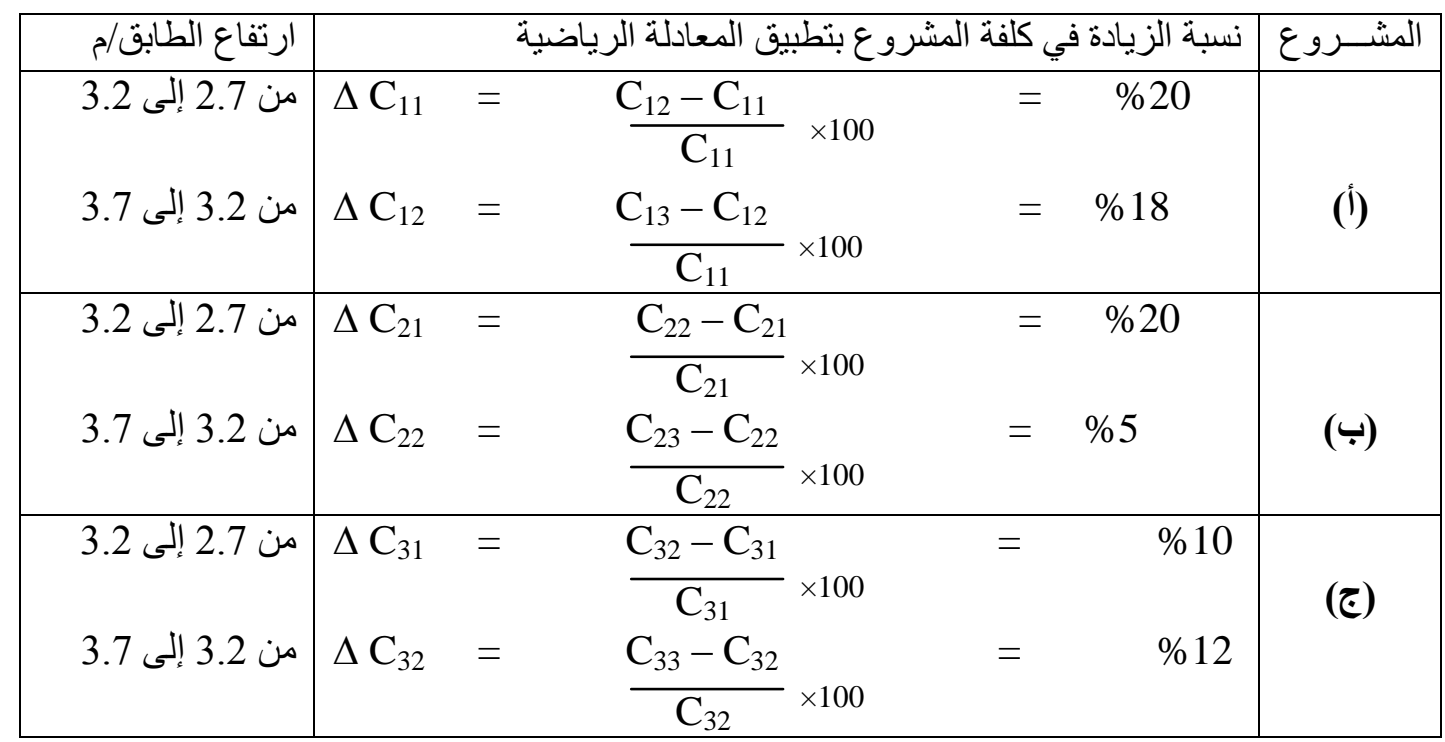


نستنتج من احتساب نسبة الزيادة في كلفة المشروع السابق أن:

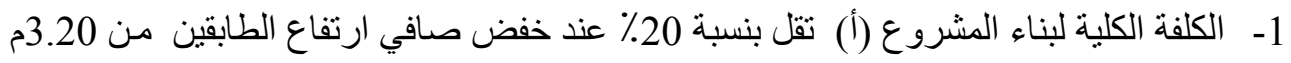

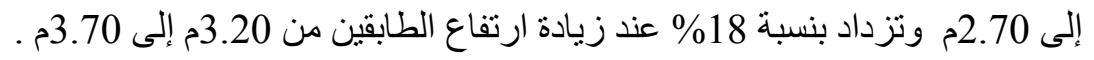

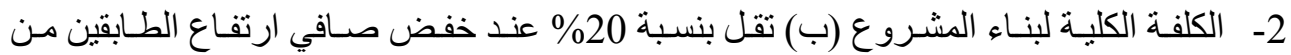

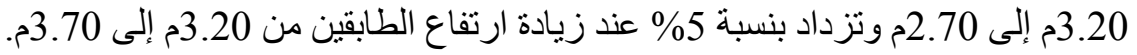

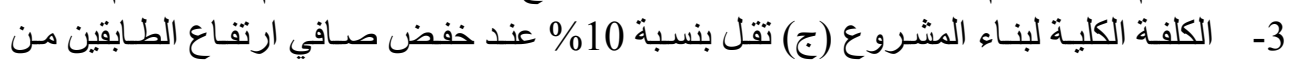

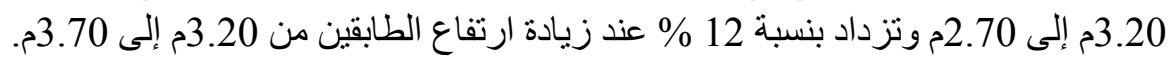

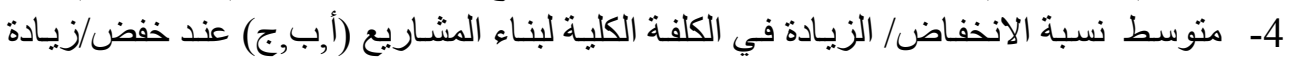

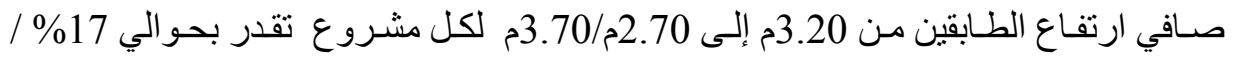

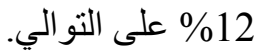

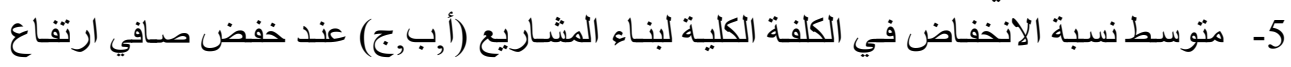
الطابقين من 3.70م إلى 2.70م لكل مشروع تقدر بحو الي 25٪

خلاصة النتائج العامة للبحث:-

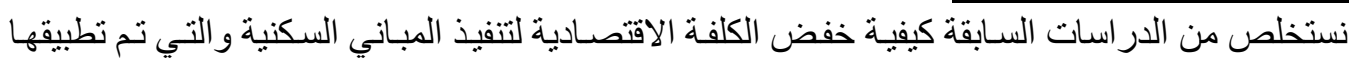

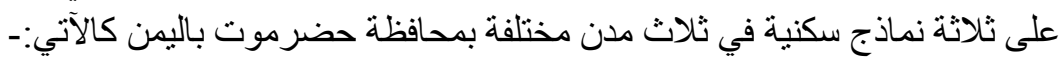

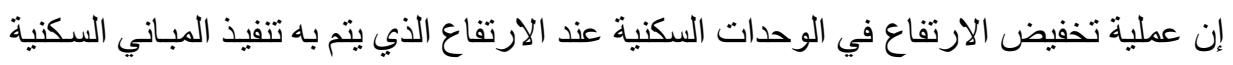

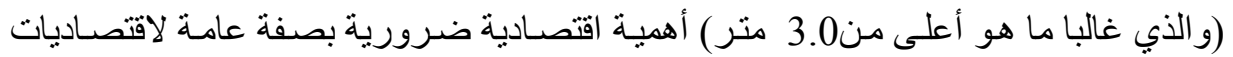
البناء وبصفة خاصة للسكان. إن در اسة هذه الوحدة الهامة يعتبر ذو أهمية تتفيذية لعدم زيادة العباء العبان على أساسـات المباني..

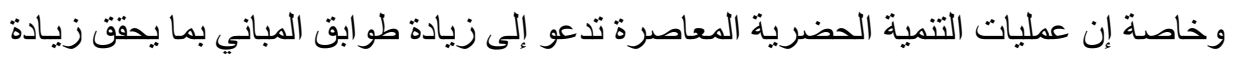

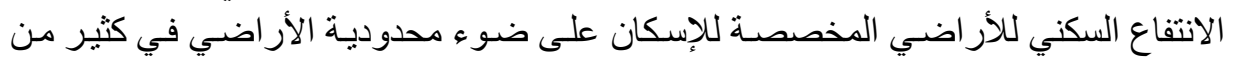
البقاع في الجمهورية اليمنية. إن زيادة السكان المضطر دة و المرتفعة باليمن تعني زيادة التوسع الأفقي لأر اضي الإنسي الإسكان في

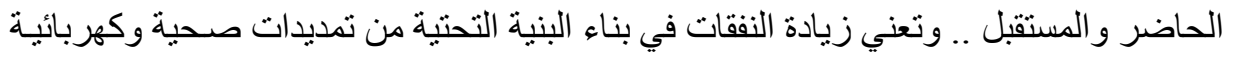

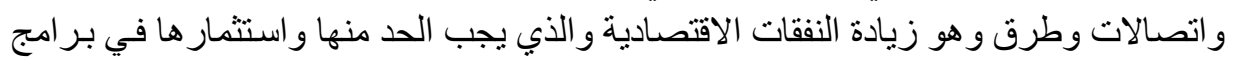

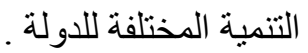
تقدر قيمة الأرض في كيفية استغلالها اقتصاديا وفي در اسـات خاصـة قدر الارتفاع الاقتصـادي

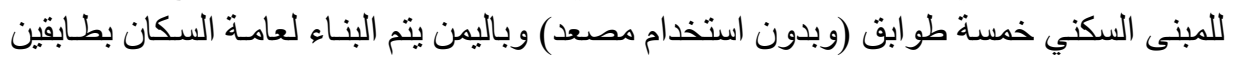

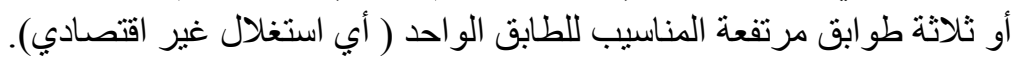

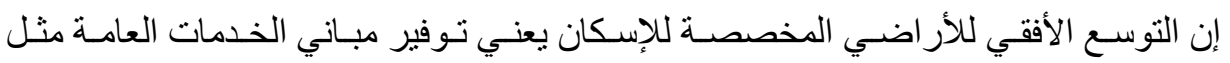

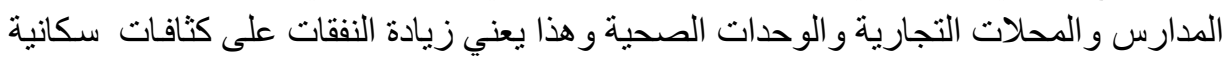

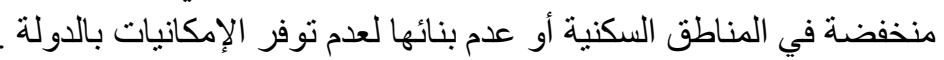

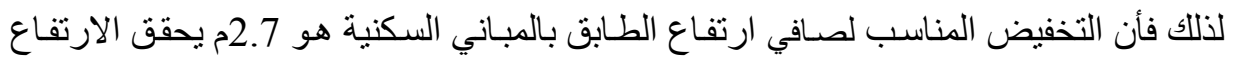

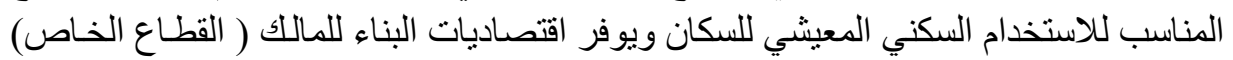

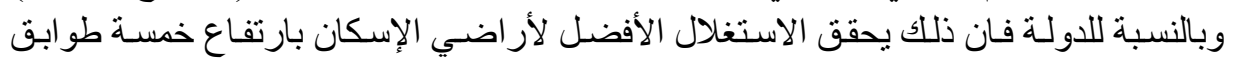

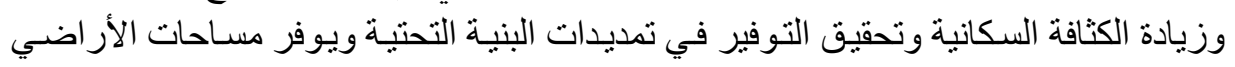




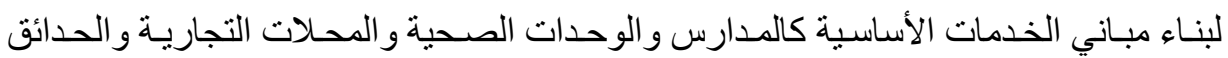
العامة بالمناطق السكنية الجديدة بالمدن اليمنية.

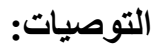

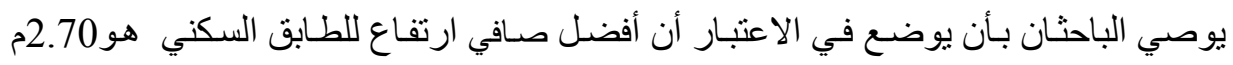

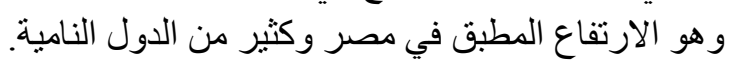

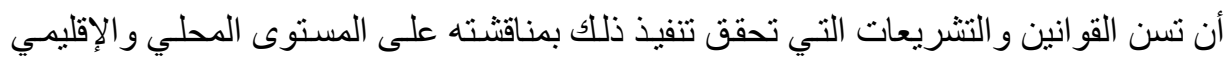

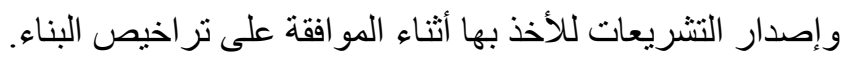

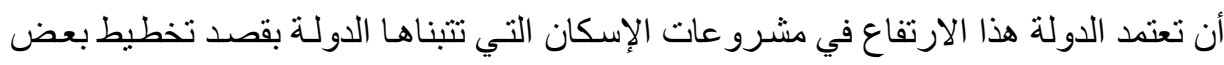

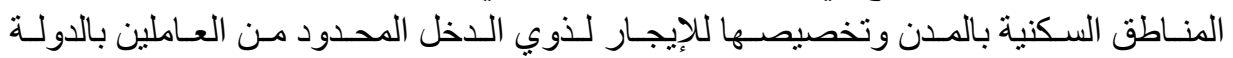
ولحديثي الزواج من الثباب.

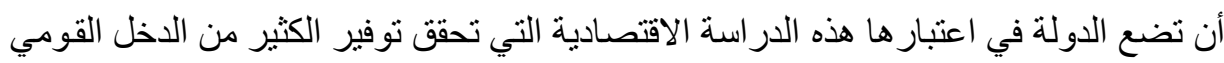

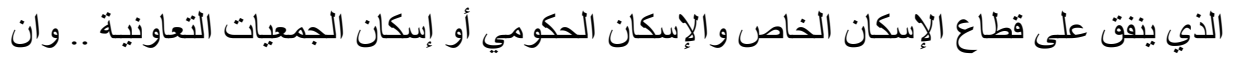

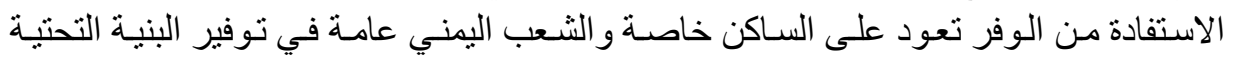
و الخدمات الأساسية بمشرو عات الإسكان.

1- ألبيني , أنور , لطفي بن شهاب , منير عبده و عبد الرحمن البريهي (2002م) ـ جداول الكميات

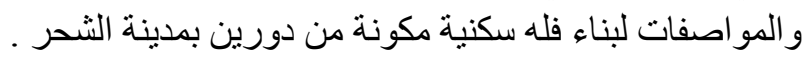

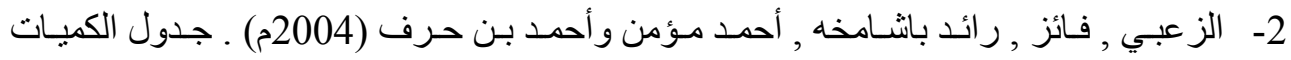

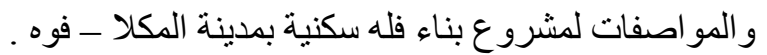

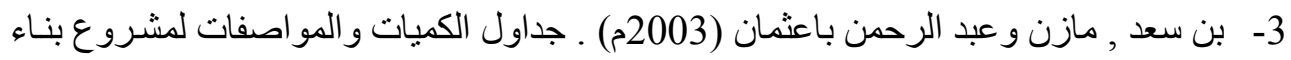

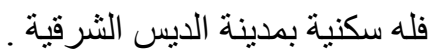
4- زين العابدين , حبيب (1997م) ـ 1934 ـ تصميم المنشئات الخر اسانية المسلحة طبقاً لنظريات المقاومـة

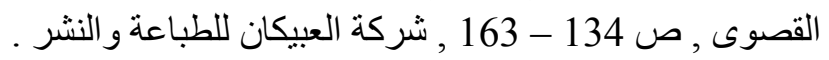

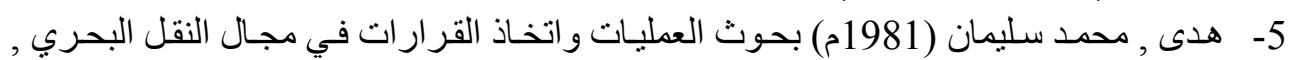
الطبعة الأولى ,ص ص 136 , الهيئة المصرية العامة للكتاب .

1المرفقات: (أمامية للمشروع (1) (1) 2. شكل رقم (4) مسقط الدور الأرضي وشكل رقم (5) مسقط الدور الأول وشكل رقم (6) واجهة

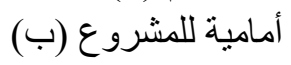
3. شكل رقم (7) مسقط الدور الأرضي وشكل رقم (8) مسقط الدور الأول وشكل رقم (9) واجهة أمامية للمشروع (7) (ج) 

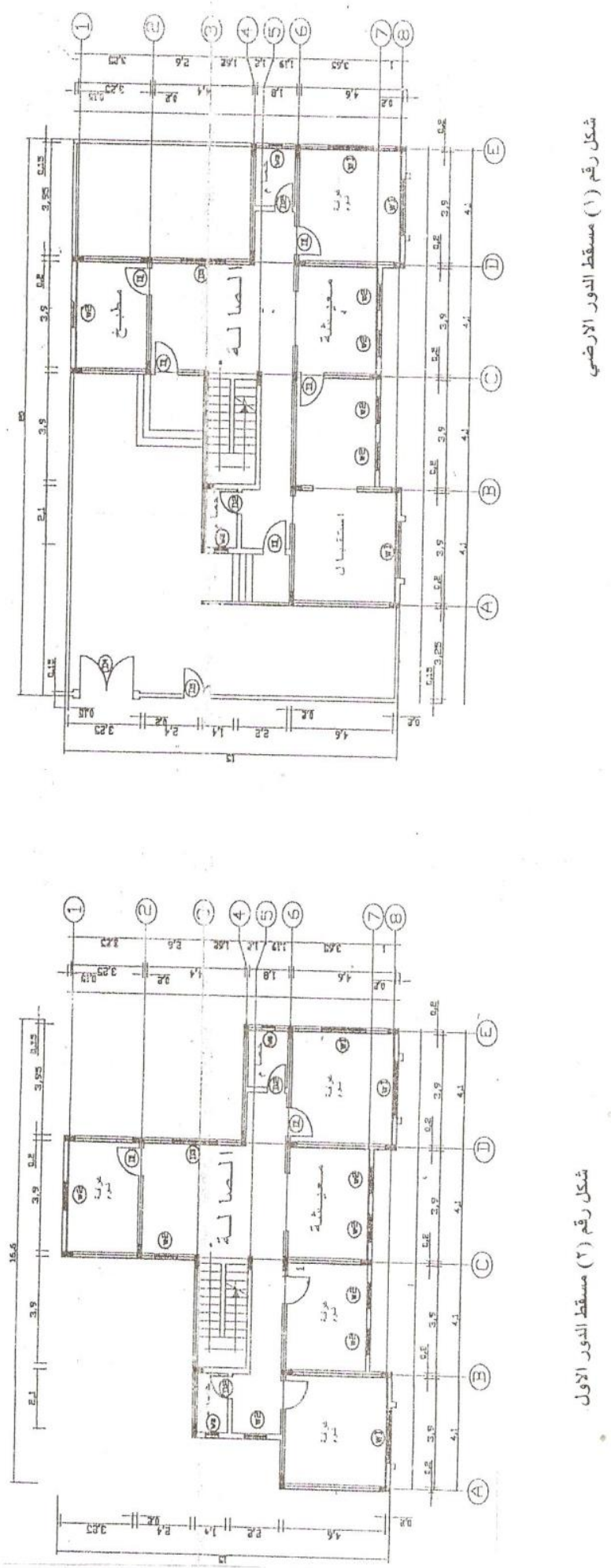


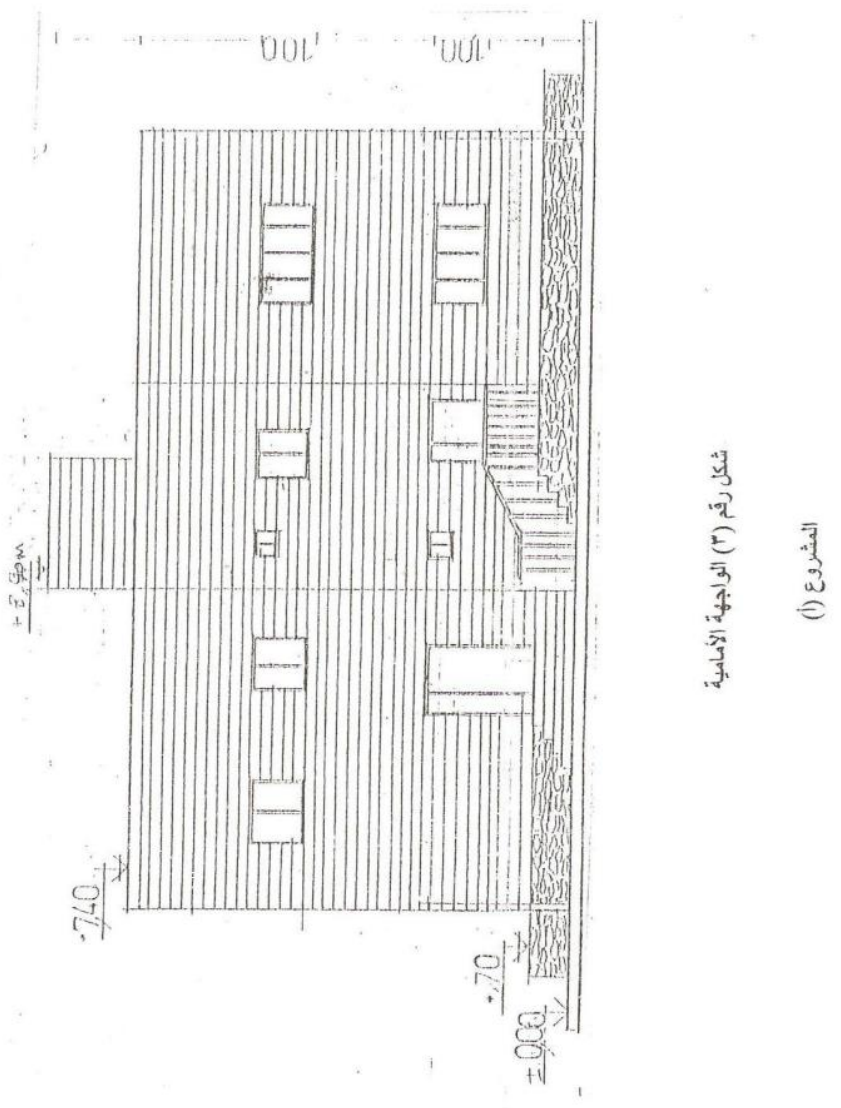



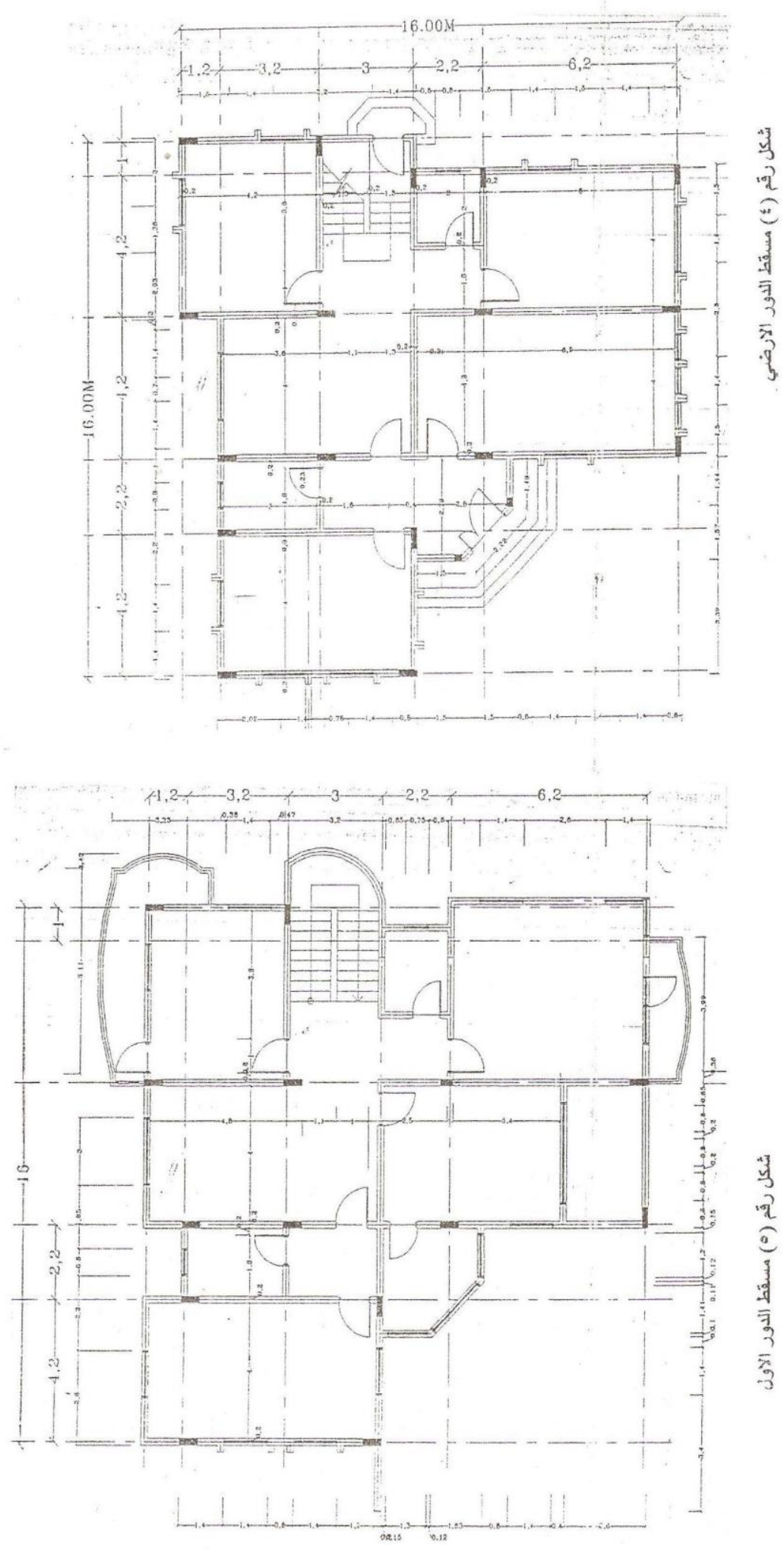


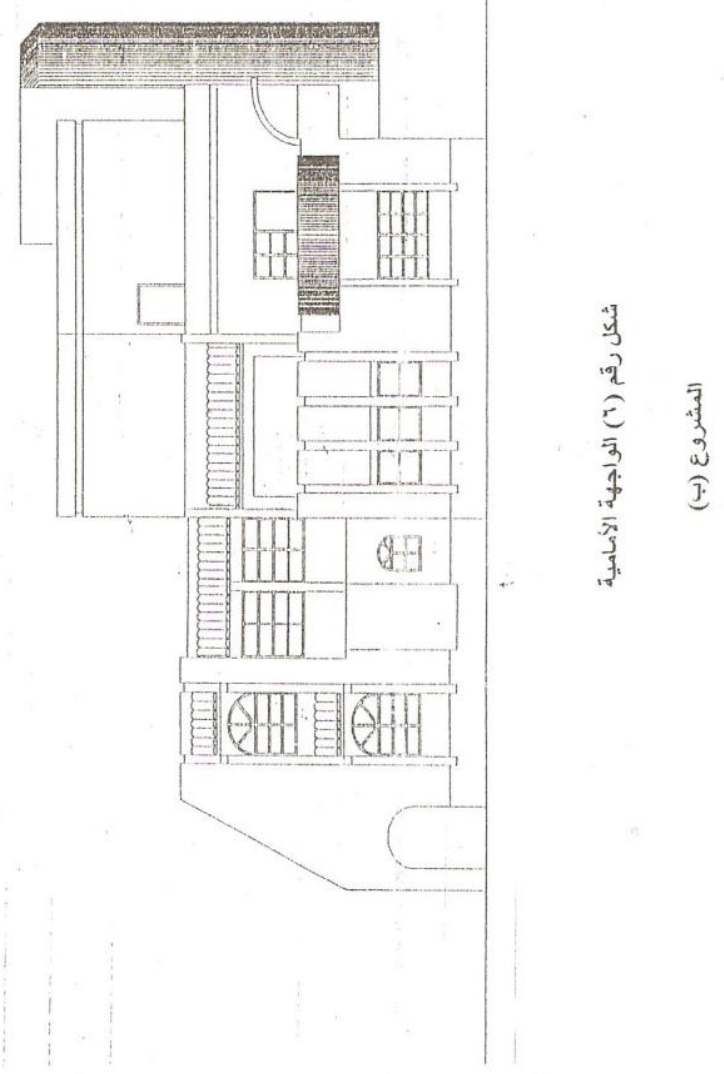



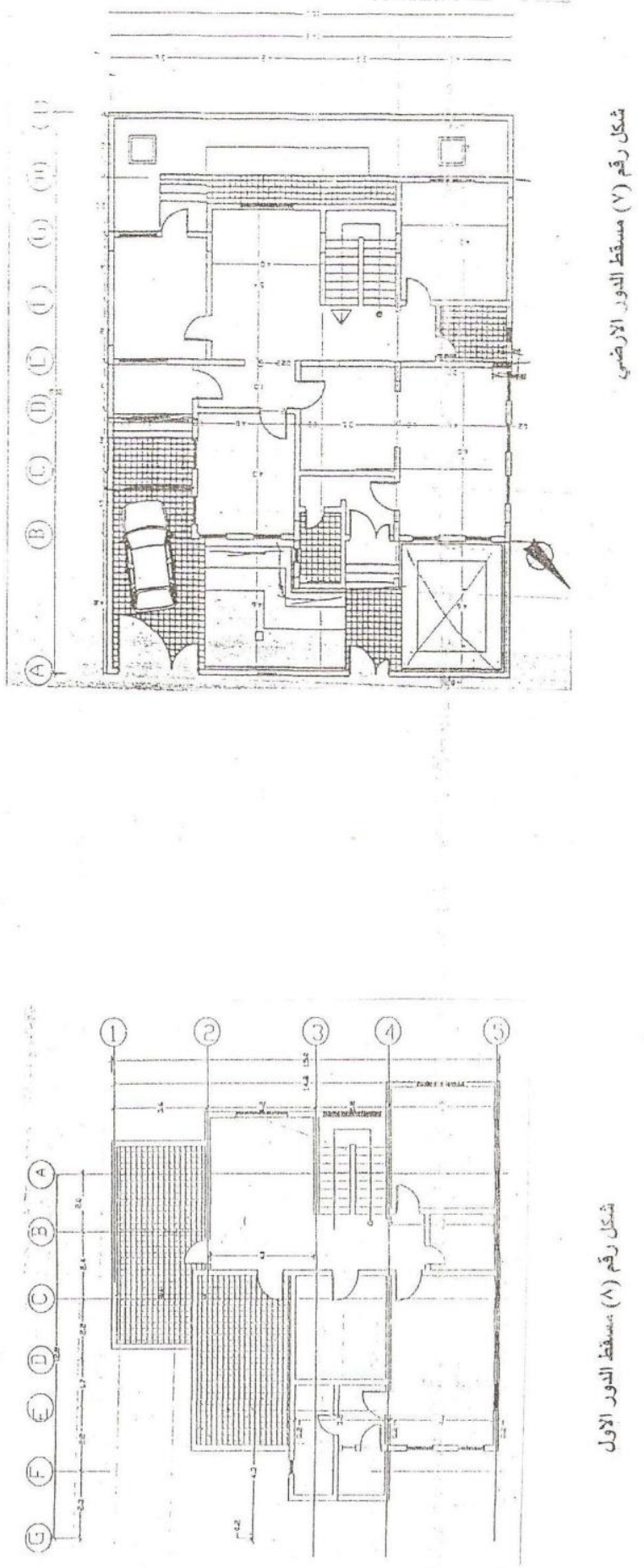


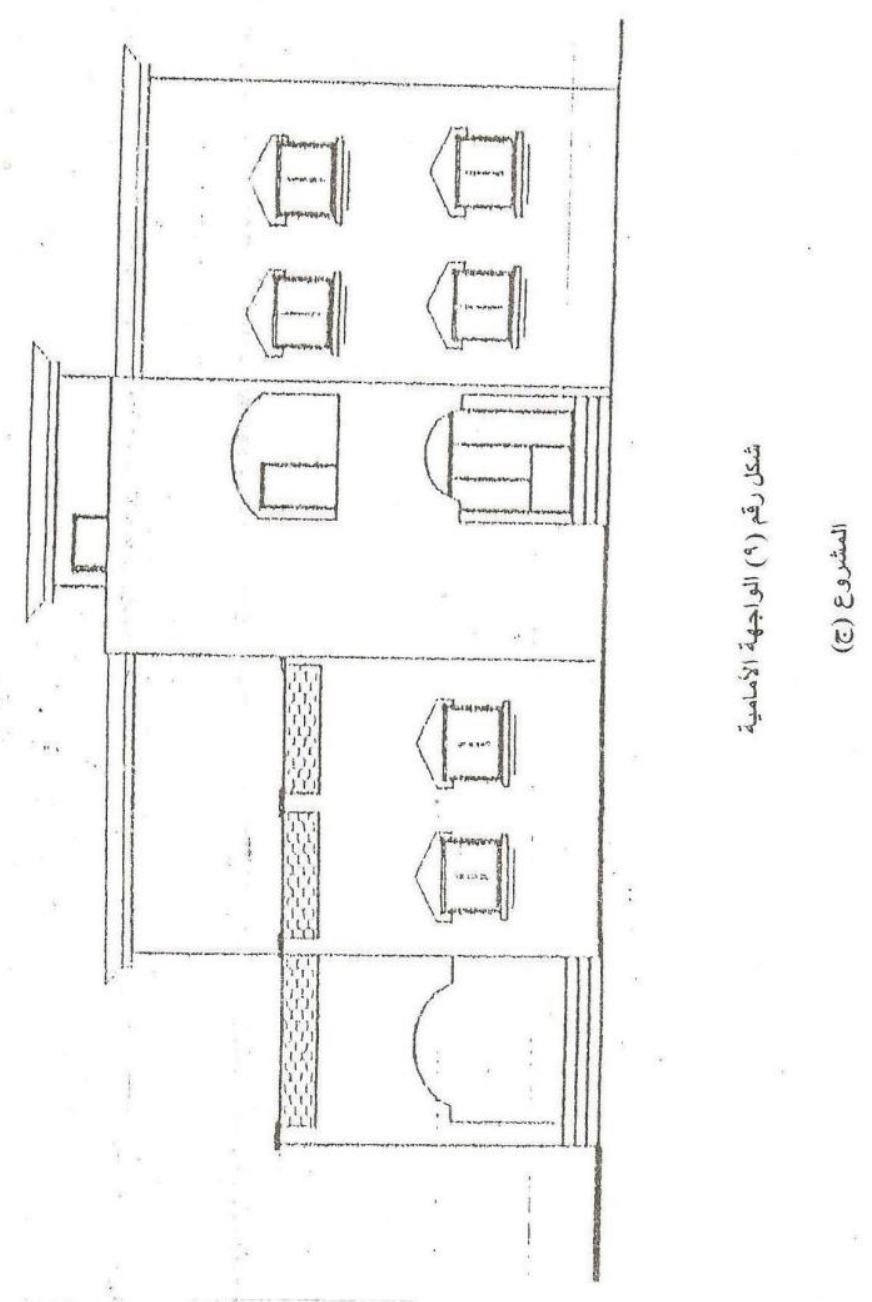

